$11-1989$

\title{
Transient Stability Hierarchical Control in Multimachine Power Systems
}

\author{
A Rubbai \\ Cleveland State University \\ F. Eugenio Villaseca \\ Cleveland State University, f.villaseca@csuohio.edu
}

Follow this and additional works at: https://engagedscholarship.csuohio.edu/enece_facpub

Part of the Controls and Control Theory Commons, and the Power and Energy Commons How does access to this work benefit you? Let us know!

\section{Publisher's Statement}

(C) 1989 IEEE. Personal use of this material is permitted. Permission from IEEE must be obtained for all other uses, in any current or future media, including reprinting/republishing this material for advertising or promotional purposes, creating new collective works, for resale or redistribution to servers or lists, or reuse of any copyrighted component of this work in other works.

\section{Original Citation}

Rubaai, A., \& Villaseca, F. E. (November 01, 1989). Transient stability hierarchical control in multimachine power systems. IEEE Transactions on Power Systems, 4, 4, 1438-1444.

\section{Repository Citation}

Rubbai, A and Villaseca, F. Eugenio, "Transient Stability Hierarchical Control in Multimachine Power Systems" (1989). Electrical Engineering \& Computer Science Faculty Publications. 86.

https://engagedscholarship.csuohio.edu/enece_facpub/86

This Article is brought to you for free and open access by the Electrical Engineering \& Computer Science Department at EngagedScholarship@CSU. It has been accepted for inclusion in Electrical Engineering \& Computer Science Faculty Publications by an authorized administrator of EngagedScholarship@CSU. For more information, please contact library.es@csuohio.edu. 
TRANSIENT STABILTTY HIERARCHICAL CONTROL IN MULTIMACHINE POWER SYSTEMS

\author{
Ahmed Rubaai, Student Member, IEEE F. Eugenio Villaseca, Member, IEEE \\ Electrical Engineering Department \\ Cleveland State University
}

\begin{abstract}
This paper presents the optimal transient stability control problem in a hierarchical structure for multimachine power systems. The two-level structure retains the local closed-loop controls, thereby easing its implementation on existing systems. The formulation accounts for nonlinearities and interconnections, and the optimization of the system transient performance is obtained at reduced computational efforts. Application of this method to a four-machine system is presented.
\end{abstract}

Keywords: Power system stability, transient stability, optimal control, hierarchical structure, nonlinearities, interconnections.

\section{INTRODUCTION}

The topic of this paper deals with a method to optimize the transient stability performance of multimachine power systems. The implication of this optimization problem lies beyond the simple stabilization of the power system. Optimal performance increases the alternative operating modes that the power system can be operated in, while still supplying a given load distribution and while still maintaining adequate system security. These alternative operating conditions may allow for more economical and more ecologically second usage of the resources avatlable to the utilities.

Recently, considerable attention has been given to the development of feasible control strategies $[1-5]$, to operate the available control means in order to drive the system from an emergency operating state into a region about its post-fault equilibrium. Meisel, et al. $[1,2]$, have attempted a systematic approach for a power system transient stability augmentation. The approach is based on an Optimal Aim Strategy (OAS) decision process, which originated in the work by Barnard [3]. The OAS is used by the local controllers to select the control forces that move a machine from a known present state towards an equilibrium state. This selection is guided by the fact that the direction of the trajectory derivative at any state depends explicitly on the value of the applied control at that time. In $[4,5]$ the task of augmenting stability is shared among several subsystems associated with their local control facilities. Adaptively, threshold limits are determined from each subsystem dominant state variables, and is an approximation to the stability margin of a subsystem. During some disturbances, the angular velocity deviation and torque angle are compared to the threshold limits. Feedback type decisions are derived from the relation of the state trajectory limits, and used to implement a bang-bang type control to load and unload generation in a subsystem.

Both methods are based on the utilization of a single machine equivalent representing the dynamics of a group of machines. However, when a system contains machines with significantly different operating characteristics and prefault conditions, control schemes based on the state trajectory of a single equivalent machine may lead to undesirable multimachine performance. Furthermore, the dynamic equivalent must be changed in response to different fault locations. This makes them difficult for on-line applications. These methods, also require that suitable supplementary controls be strategically placed throughout the system. The control scheme presented here is a two-level hierarchical structure involving local feedback controllers and a central coordinating controller. A few studies have used this approach [6-9], but their work has dealt with the linearized regulation problem and not the nonlinear transient stability problem. The approach described in this paper utilizes the hierarchical coordination scheme presented in [10], which is a generalization of that in [11]. It decomposes the overall problen into subproblems that may be solved simultaneously using parallel computations. The two-level structure retains the local closed-loop controls, thereby easing its implementation on existing systems. The coordination of the local feedback controls by the central controller, accounts for nonlinearities and interconnections, and yields the global optimization of the system transient performance.

\section{PHYSICAL DESCRIPTION OF THE MATHEMATICAL MODEL}

Before introducing a mathematical formulation for the control strategy, a physical explanation is presented in this section to help clarify the concepts. The technique proposed in this paper assumes that an on line capability for computing the post-fault equilibrium state is available. Such a method has been presented by Smith [12], where measured power flows are used for the fast prediction of this post-transient steady-state or "target state". Since the system model is an approximation to the real power system, the calculated post-fault equilibrium state, which we call the "desired state" and denote by $x$, can only be guaranteed in some neighborhood of the actual equilibrium state. Furthermore, we also assume that the multimachine system at time $t=0$, corresponding to the instant of fault removal, has a known initial st-te $x(0)=x$. Several techniques for the on-line monitoring of the current system state have been reported in the literature $[13,14,15,16]$. Therefore, the assumptions of known initial and desired states appear to be feasible.

In the two-level control hierarchy, the local controllers associated with each subsystem constitute level 1, and the central coordinating controller forms level 2. Information avallable to level 2 includes the dynamical model for the entire system, the global as well as the local costs, the values of initial and current states. Feasibility of the coordination effort requires that level 2 be capable of choosing its control strategy before the local controllers choose theirs. The global strategy is to minimize the overal1 
systen cost functional.

This policy is communicated down to the local feedback controllers in level 1 , which in turn opt imize the performance of their own subsystems. The system control variables are the steam input powers to the turbines. The regulation of these input powers has a direct effect on the rotor swings under transient conditions.

The nonlinear differential equations describing the transient behavior of an n-machine system are:

$$
\begin{aligned}
& \dot{\delta}_{i}=\omega_{j} \quad i=1,2, \ldots, n \\
& \dot{\omega}_{i}=\frac{1}{M_{i}}\left(A_{n_{i}}-P e_{i}-D_{j} \omega_{j}+U_{i}\right)
\end{aligned}
$$

where $U_{i}$ represents an additive local power control for the $i-$ th machine, and

$$
P e_{j}=E_{i} G_{i j}+E_{i} \sum_{\substack{j=1 \\ j \neq i}}^{n} E_{j}\left(G_{i j} \cos \delta_{i j}+B_{i j} \sin \delta_{i j}\right)
$$

Please refer to the appendix for a definition of each of these terms. Taking the $n$-th machine as reference, the state vector for the ith machine is defined by

$$
\begin{aligned}
x_{i} & =\left(\delta_{i n}, w_{i n}\right)^{\top} \\
& =\left(x_{1 i}, x_{2 j}\right)^{\top}
\end{aligned}
$$

With this definition, equations (1) and (2) become

$$
\begin{aligned}
\dot{X}_{i}=A_{i} X_{i}+b_{i} U_{i}+f_{i}(x) & +h_{i}\left(x_{1 j}\right) \\
i & =1,2, \ldots, n-1
\end{aligned}
$$

where the overall state vector is equal to

$$
\begin{aligned}
x & =\left(s_{1 n}, \delta_{2 n}, \ldots, \delta_{n-1, n}, w_{1 n}, w_{2 n}, \ldots, w_{n-1, n}\right)^{\top} \\
& =\left(x_{11}, x_{12}, \ldots, x_{1, n-1}, x_{21}, x_{22}, \ldots, x_{2, n-1}\right)^{\top}
\end{aligned}
$$

and

$$
A_{i}=\left[\begin{array}{cc}
0 & 1 \\
0 & \frac{-D i}{M_{i}}
\end{array}\right], b_{i}=\left[\begin{array}{c}
0 \\
\frac{-1}{M_{j}}
\end{array}\right]
$$

The term $f_{i}(x)$ represents the interconnection effects on the ith subsystem by the other subsystens, and is given by

$$
\begin{aligned}
f_{i}(x)=\frac{-1}{M_{i}} \sum_{\substack{j=1 \\
j \neq 1}}^{n-1} E_{i} E_{j}\left[G_{i j} \cos \left(x_{1 i-x_{1 j}}\right)+B_{i j} \sin \left(x_{1 i-x_{1 j}}\right)\right] \\
\quad+\frac{1}{M_{n}} \sum_{j=1}^{n-1} E_{j} E_{n}\left[-G_{j n} \sin x_{1 j}+B_{j n} \cos x_{1 j}\right]
\end{aligned}
$$

The term $h_{j}\left(x_{1} i\right)$ includes only the nonl inearities of the ith subsystem, and is equal to

$$
\begin{aligned}
h_{i}\left(x_{1 i}\right)=\frac{-1}{M_{i}} E_{i} E_{n}\left(G_{i n} \cos x_{1 i}+B_{i n} \sin x_{1 i}\right) \\
+\frac{1}{M_{i}}\left(P_{m_{i}}-E_{i}^{2} G_{i j}\right)-\frac{1}{M_{n}}\left(P_{m_{n}}-E^{2} G_{n n}\right) \\
\text { PERFORMANCE MEASURES }
\end{aligned}
$$

level 1 is defined on appropriate sets of admissible trajectories. The state trajectories start at the initial states at the time of fault removal, and end at fixed points at the desired states, defined as the post-fault equilibrium states, at $t$ ime $t f$.

A quadratic term included in the cost functional is the deviation of each of the states in the state vector from their post-fault equilibrium condition. The weighting matrix on the state deviations is assumed positive definite.

The other term in the cost functional penalizes the control effort. The weighting matrix on the control is chosen as pos it ive definite.

Thus, the performance measure for the i-th subsystem in level 1 is

$$
\begin{aligned}
& J_{i}=1 / 2 \int_{0}^{t_{f}}\left[\left(x_{i}-x_{j}\right)\right.\left.Q_{i}\left(x_{j}-x_{j}\right)+U_{j}^{T} R_{j} U_{j}\right] d t \\
& \text { for } i=1,2, \ldots, n-1
\end{aligned}
$$

The overall objective function in level 2 is separable, and therefore equal to the sum of the local perforinance measures. That is

$$
J=\sum_{i=1}^{n-1} j_{i}
$$

\section{HIERARCHICAL OPTIMIZATION}

The coordinated minimization of each subproblem is obtained as follows. Level 2 initializes the process by generating a constant state trajectory, equal to the initial state $x^{0}$ over the interval $\left[0, t_{f}\right]$, and sets the Lagrange multipliers equal to zero. This information is received by Level 1, where the optimization problem reduces to that of solving $n-1$ independent subproblems. At the $k$-th iteration these problems have the form.

$\min u_{i}^{k}=1 / 2 \int_{0}^{t}\left[\left(x_{i}-x_{i}^{d}\right)^{\top} Q_{i}\left(x_{i}-x_{i}^{d}\right)+U_{i}^{\top} R_{i} U_{i}+\right.$

$$
\left.\left(x_{i}-x_{i}^{k}\right)^{\top} v_{i}\left(x_{i}-x_{i}^{k}\right)\right] d t
$$

Subject to the subsystem dynamics

$$
\dot{x}_{i}=A_{i} x_{i}+b_{i} u_{i}+h_{i}\left(x_{1 j}^{k}\right)+f_{i}\left(x^{k}\right)
$$

and the equal ity constraint $x_{i}=x_{i}^{k}$

The set of resulting state trajectories are used by Level 2 to compute the error between the predicted and the received state trajectories. This error is then used to produce a set of predicted state trajectories and Lagrange multipliers. Note that this same error term has been added to (4) shown in (6) as a penalty term.

In order to solve the local problems, the maximum principle $[17,18]$ is used. Appending (7) and (8) as equal ity constraints to the local performance measure (6) through suitable mult ipliers, the Hamiltonian takes the form

$$
H^{k}=\sum_{i=1}^{n-1} H_{j}^{k}
$$

where the sub-Hamiltonians can be written as 
$H_{i}^{k}=\frac{1}{2}\left(x_{i}-x_{i}^{d}\right)^{\top} Q_{j}\left(x_{i}-x_{i}^{d}\right)+\frac{1}{2} U_{i}^{\top} R_{i} U_{i}+\frac{1}{2}\left(x_{i}-x_{i}^{k}\right)^{\top} V_{i}\left(x_{i}-x_{i}^{k}\right)$

$+p_{i}^{T}\left(A_{j} x_{j}+b_{j} u_{j}+h_{j}\left(x_{1 j}^{k}\right)+f_{j}\left(x^{k}\right)\right)+\left(\pi_{i}^{k}\right)^{\top}\left(x_{j}-x_{j}^{k}\right)$

The optimization problem can only be considered solved when two conditions are sat isfied: 1) the computed state trajectories turn out to be the same as the ir predicted values, for a given vector function $\pi$; and 2) a value for $\pi$ has been found which opt imizes the sum of the local performance measures.

Level 2 therefore carries two nested opt imization processes. The outer one searches for a set of Lagrange multipliers $\pi i$, and the inner one searches the state trajectory space to sat isfy the constraints. One of the most effect ive means for updating $\pi i$ is the equal ity updat ing method [19]. The $i-t h$ Hamiltonian is extremized with respect to $x_{j}$ and $\pi_{i}$, yields

$$
\begin{aligned}
& x_{i}^{k}=x_{i} \\
& \pi_{i}^{k}=-v_{i}\left(x_{i}-x_{i}^{k}\right)+\left.\frac{\partial}{\partial x_{i}}\left[h_{i}^{\top}\left(x_{1 j}\right)+f_{i}^{T}(x)\right]\right|_{x_{i}=x_{i}^{k}}\left(k_{i} x_{i}+s_{i}\right)
\end{aligned}
$$

The application of the optimality conditions to Level 1 subproblems yields the following equations

$\dot{x}_{i}=A_{j} x_{i}-b_{j} R_{i}^{-1} b_{j}^{T} k_{j} x_{j}-b_{j} R_{j}^{-1} b_{j}^{T} S_{j}+h_{i}\left(x_{1 j}^{k}\right)+f_{j}\left(x^{k}\right)$

$x_{i}(0)=x_{i 0}$

$\dot{K}_{j}=-A_{j}^{T} K_{j}-K_{j} A_{j}+K_{j} b_{j} R_{i}^{-1} b_{j}^{T} K_{i}-\left(Q_{j}+V_{j}\right)$

$K_{j}\left(t_{f}\right)=0$

$\dot{S}_{j}=\left(K_{j} b_{j} R_{j}^{-1} b_{j}^{T}-A_{i}^{T}\right) S_{j}-K_{j} h_{j}\left(x_{1 j}^{k}\right)-K_{j} f_{j}\left(x^{k}\right)$

$$
+V_{i} X_{j}^{k}+Q_{i} X_{i}^{d}-\pi_{i}^{k}
$$

$s_{i}\left(t_{f}\right)=0$

$U_{i}=-R_{j}^{-1} b_{j}^{T} K_{j} x_{j}-R_{j}^{-1} b_{j}^{T} S_{i}$

To compute the feedback control law of (15), it is necessary to integrate (13) and (14) independent $1 y$ and backwards in $t$ ime with $K_{i}\left(t_{f}\right)=0$, and $S_{i}\left(t_{f}\right)=0$, respectively, using the prediction vector generated by level 2. The results are sent upward to update these variables. At the end of the optimization process, the result ing $K_{j}, X_{i}$, and $S_{j}$ are used to obtain the local opt imal closed-loop control.

\section{NUMERICAL RESULTS}

To prove feasibility of concept the 4-machine 10bus test system pesented in [20], was used. The oneline diagram is shown in Figure 1. The generator at bus 10 is cons idered to be the reference un it since it has a relatively large MW capacity (compared to other generating machines at buses 7,8 and 9), with $\delta_{1}=0.0014$ rad. Please refer to the Appendix for data pertaining this system.

A 3-phase to ground fault is considered on the 1 ine between buses 3 and 4 , near bus 3 . This is the worst possible location for the fault in the transmission system. The fault is cleared by the opening of the circuit breakers at both ends of the 1 ine between buses 3 and 4 , thus leaving mach ine 8 with only a weak link to the rest of the system. The critical clearing $t$ ime is approximately $0.4244 \mathrm{sec}$ for the uncontrolled system. For a fault-clearing time of 0.4377 secs., mach ine 8 accelerates away from the other three machines and loses synchronism with the rest of the system. Figure 2 shows the state trajectories $\delta 7$, $\delta_{8}$ and $\delta 9$. Thus this is a good case to test the usefulness of our control strategies. The initial states, and the final desired states for this problem are given in Table 1.

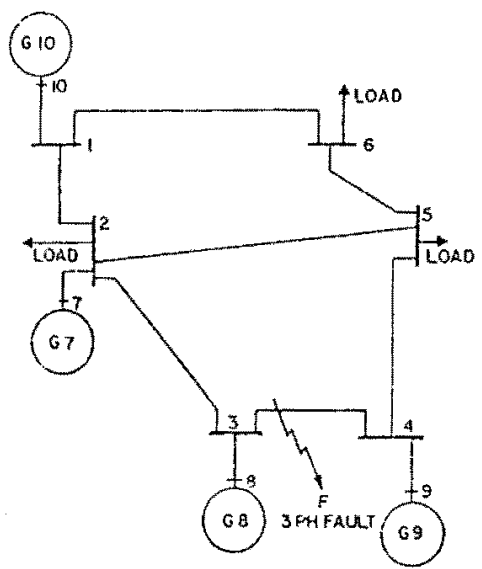

Figure 1. One-line diagram.

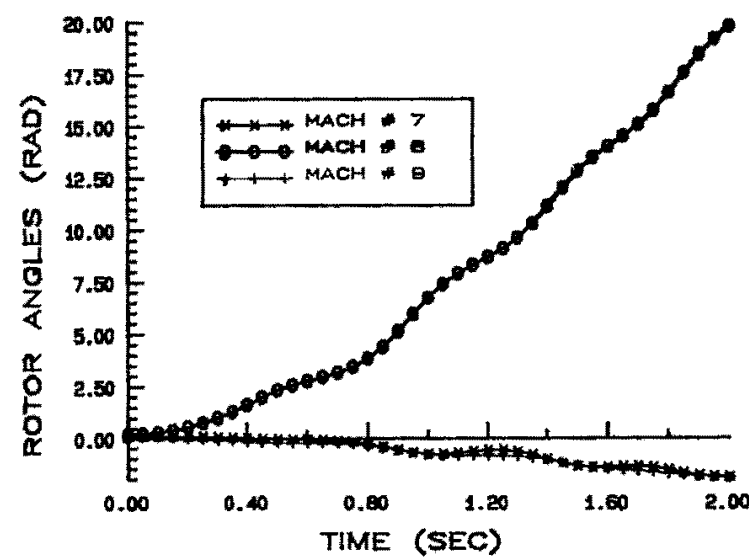

Fioure 2. State trajectories for fault cleared at $0.4377 \mathrm{sec}$

TABLE

Four-Mach ine In it ial and Desired States

\begin{tabular}{c|c|c|c|c|c|c} 
& ${ }^{67} \mathrm{rad}$ & ${ }^{8}{ }_{\mathrm{rad}}$ & ${ }^{89} \mathrm{rad}$ & ${ }^{\omega} \mathrm{rad}_{\mathrm{sec}}$ & ${ }^{6 \mathrm{~g}} \mathrm{rad} / \mathrm{sec}$ & ${ }^{\omega g_{\mathrm{rad}} / \mathrm{sec}}$ \\
\hline $\begin{array}{c}\text { Initial } \\
\text { State }\end{array}$ & -0.01862 & 1.89815 & -0.18245 & -0.00021 & 0.01291 & 0.000046 \\
\hline $\begin{array}{c}\text { Des ired } \\
\text { State }\end{array}$ & 0.1024 & 0.2411 & 0.05197 & 0 & 0 & 0
\end{tabular}

The simulation of the proposed control structure on the system, under identical conditions, leads to the following abservations. The resulting rotor angles versus time are shown in Figure 3 , with the corresponding power controls versus time shown in Figure 4. Note that the swing curves are quite stable, with generator 8 nicely damped, and rema in near their 
respective desired state values. The control function of machine 8 starts at its minimum value of -0.85 p.u. power, is then gradually damped, finally reaching zero. This solution is obtained with $R=$ diag $(1001010), Q$ $=\operatorname{diag}(55)$, and $\underline{V}=\operatorname{diag}(0.01-0.01)$.

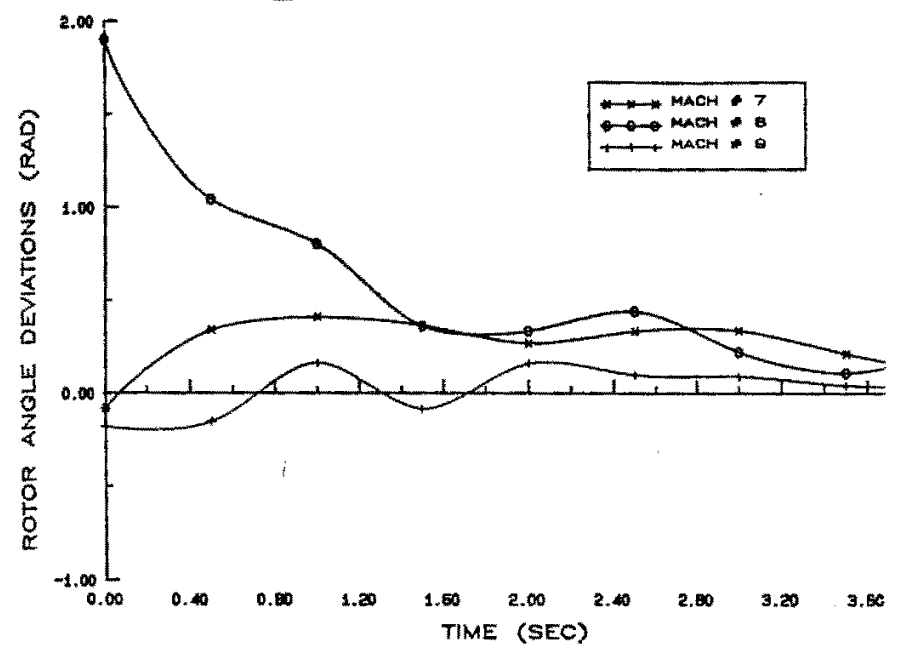

Figure 3. Optimal state trajectories for $0.4377 \mathrm{sec}$. clearing time

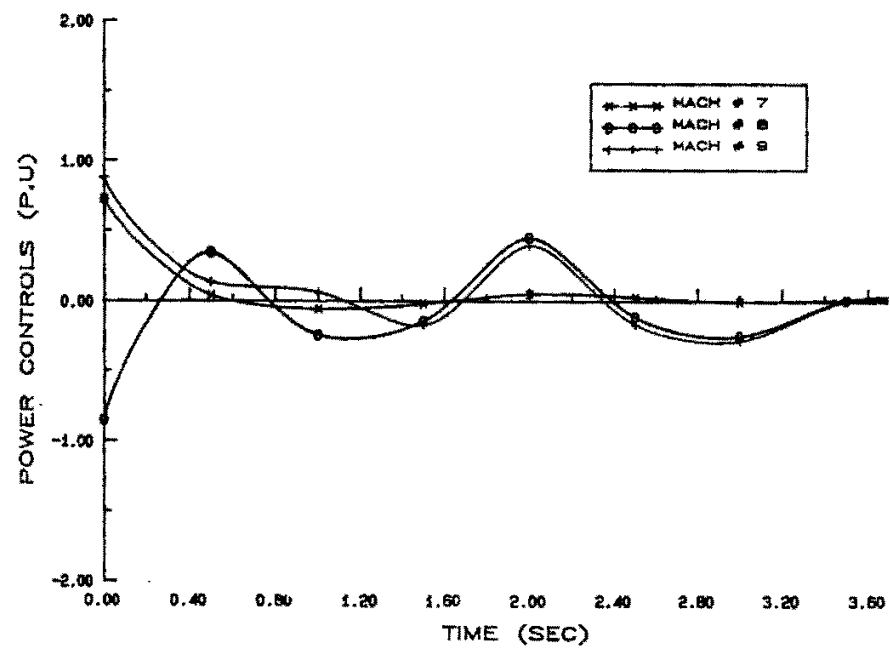

Figure 4. Cptimal control trajectories for 0.4377 sec. clearing time

Several additional tests were run for the same fault and performance measure but different fault clearing times. Due to 7 imitations of space only one such test is included here, which will depict the effectiveness of the proposed control strategy. Figures 5 and 6 show the deviations in rotor angles and control efforts, respectively, corresponding to a clearing time of 0.79578 seconds. In spite of the increased severity of the fault condition, the rotor angles settle to the desired values as in the previous case, but with even better damping. Also, the control efforts are much smoother. These are very important characteristics of the proposed technique, which contrast with those reported in the literature $[4,5,13,14]$, where the effectiveness of control actually deteriorates or is expected to deteriorate with the severity of the fault condition.

Testing of this technique on utility size systems is under current consideration. This effort is not expected to pose any problems given that the prototype program is modular. That is, the modifications required to handle systems of different sizes and characteristics can easily be implemented without need to reformulate the entire procedure.

\section{CONCLUS IONS}

In this paper, a two-level hierarchical structure is proposed to optimize the control of transient swings in multimachine power systems. This control technique involves a number of independent local controllers communicating with a central coordinating controller, which accounts for nonlinearities and interconnections and yields the global optimal transient performance. Since the computations are distributed among the many local feedback subsystems, the storage and solution times are considerably less than those required by a single overall centralized controller. This advantage becomes much stronger as the system size increases.

For illustration purposes, this technique was applied successfully to a 4-machine system.

Although this paper considers a separable global cost functional, this is not an essential requirement. A cost functional based on an energy type function would al so be solvable, but at the expense of more information transfer between levels.

\section{ACKNOWLEDGEMENTS}

The authors would like to thank the anonymous reviewers for their helpful comnents.

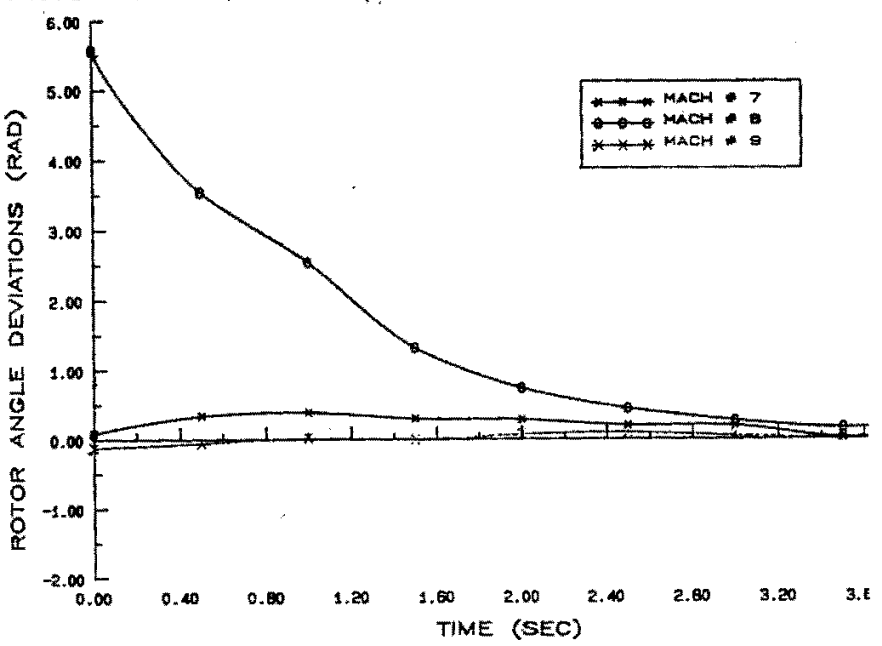

Figure 5. Optimat state trajectories for 0.79578 sec. clearing time

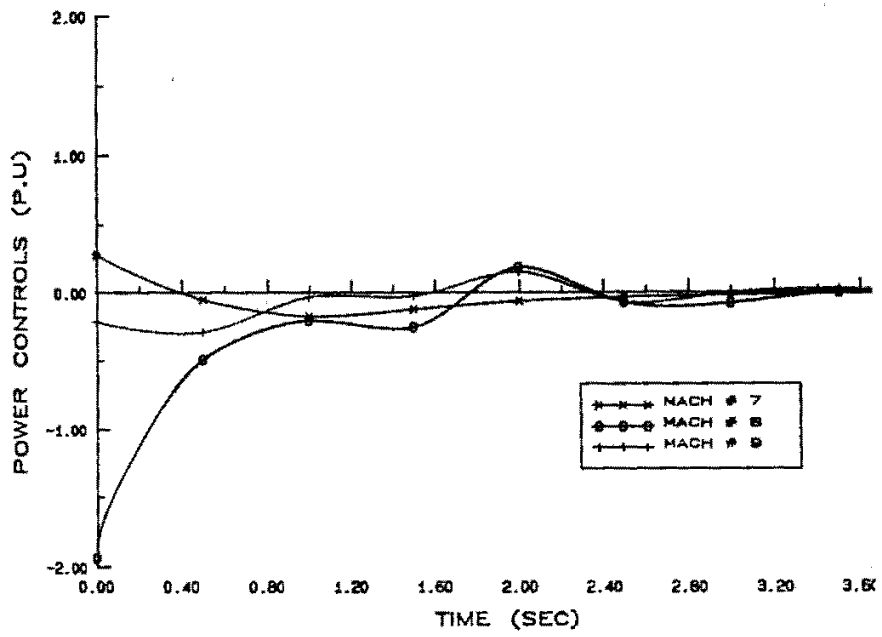

Figure 6. Optinal control trajectories for 0.79578 sec. clearing time

\section{APPENDIX}

\section{List of Symbols}

$H_{j}=\quad$ inertia constant of $i$-th machine

$M_{i}=(4 \pi f) H i$ 
$D_{i}=(2 \pi f) d i(d i=$ damping coefficent of $i-t h$ machine)

$E_{i}=$ magnitude of the voltage behind transient reactance of $\boldsymbol{j}$-th machine

$\delta_{j}=$ rotor angle of $i$-th machine

$\omega_{i}=$ rotor speed of $i-t h$ machine

$P_{e j}=$ electrical output power to $i$-th machine

$P_{m i}=$ mechanical input power to $\boldsymbol{i}$-th machine

$G_{i j}=$ driving point conductance at machine $i$

$G_{i j}=$ the mutual conductance between machine $i$ and $j$

$B_{i j}=$ the mutual susceptance between machine $i$ and $j$

$U_{i}=$ power control for machine $i$-component $i$ of $U$

$t_{f}=$ time interval over which the control is active

$x=\quad$ a state vector with values in $R^{2(n-1)}$

$R^{2(n-1)}=2(n-1)$ dimensional Euclidean space

\section{SYSTEM DATA}

TABLE I TRANSMISSION LINE CONSTANTS FOR THE SYSTEM (in pu of 100 MVA base)

\begin{tabular}{cccc}
\hline From Bus & To Bus & R(p.u.) & $x(p . u)$. \\
\hline 1 & 2 & 0.05 & 0.20 \\
2 & 3 & 0.10 & 0.50 \\
3 & 4 & 0.20 & 0.80 \\
4 & 5 & 0.10 & 0.30 \\
5 & 6 & 0.20 & 0.40 \\
6 & 1 & 0.10 & 0.15 \\
2 & 5 & 0.20 & 0.50 \\
\hline
\end{tabular}

TABLE II LOADS ON THE SYSTEM (on 100 MVA base)

\begin{tabular}{ccc} 
At Bus & $P\left(p . u_{0}\right)$ & $Q\left(p . u_{.}\right)$ \\
\hline 2 & 0.20 & 0.10 \\
5 & 0.40 & 0.15 \\
6 & 0.30 & 0.10 \\
\hline
\end{tabular}

\begin{tabular}{|c|c|c|c|c|}
\hline $\begin{array}{l}\text { Generator } \\
\text { Number }\end{array}$ & $\begin{array}{c}\text { MVA } \\
\text { Capacity }\end{array}$ & $\stackrel{M}{p . u}$ & $\begin{array}{l}x_{d}^{\prime} \\
\text { p.u. }\end{array}$ & $\begin{array}{c}\text { D } \\
\text { p.u. }\end{array}$ \\
\hline 10 & 100 & 75,350 & 0.004 & 1.0 \\
\hline 7 & 15 & 1,130 & 1.00 & 12.0 \\
\hline 8 & 40 & 2,260 & 0.500 & 2.5 \\
\hline 9 & 30 & 1,508 & 0.400 & 6.0 \\
\hline
\end{tabular}

[1] Meisel, J., "Transient Stability Augmentation Using a Hierarchical Control Structure," IEEE Iransaction on Power Apparatus and Systems, VoT. PAS-99, pp. 256-263, January/February 1980.

[2] Meisel, J., Sen, $A_{\text {., }}$ and Gilles, M. L., "Alleviation of a Transient Crisis Using Shunt Breaking Resistors and Series Capacitors," International Journal of Electric Power and Energy Systems, Vol.3, No. 1, pp. 25-37, January 1981.

[3] Barnard, R. D., "An 0ptimal-Aim Control Strategy for Nonl inear Regulation Systems," IEEE Transaction on Automatic Control, Vol. AC-20, No. 2, pp. 200-208, Aprin 1975.

[4] Aliyu, U. 0., and El-Abiad, A. H., "A Local Control. Strategy for Power System in Transient State, Part I: Functional Design," IEEE Transaction on Power Apparatus and Systems, Vol. PAS-101, No. 11, pp. 4245-4253, November 1982.

[5] Aliyu, U. 0., and El-Abiad, A. H., "A Local Control Strategy for Power System in Transient State, Part II: Implementation and Test Results by Simulation," IEEE Transaction on Power Apparatus and Systems, Vol. PAS-101, No. 11, pp. 4254-4262, November 1982.

[6] Mansour, M. O., and El-Abiad, A. H., "Hierarchical Control of Interconnected Power System," Proceedings of

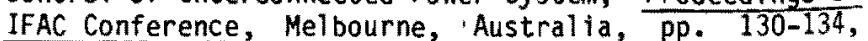
February 1977.

[7] Abdal-Magid, Y. L., and Aly, G. M., "Two-level Optimal Stabilization in Multimachine Power Systems," Electric Power System Research, Vol. 6, pp. 33-41, 1982.

[8] Soliman, H. M., and Darwish, D., "Decentralized and Hierarchical Stabilization Technique for Interconnected Power Systems," Large Scale Systems, Vol. 2, pp. 113-122, 1981 . 
[9] Sastry, S., and Varaiya, P., "Hierarchical Stability and Alert State Streeing Control of Interconnected Power Systems," IEEE Transaction on circuits and systems, Vol. CAS-27, No. 1!, pp. 1102-1112, November 1980 .

[10] Hassan, M. F., and Singh, M. G., "Hierarchical Successive Approximation Algorithm for Nonlinear Systems, Part I: Generalization of the Method of Takahara," Large Scale Systems, Vol. 2, pp. 65-79, 1981.

[11] Mesarovic, M. D., Mako, D., and Takahara, Y., "Theory of Hierarchical Multi-level Systems", Academic Press, New York, 1970. [12] Smith, 0.J.M., "rpower System State Estimation," IEEE Transactions on Power Apparatus and Systems, Vol. PAS-89, No, 3, pp. 363-379, March, 1970.

[12] Smith, 0. J., "Power System State Estimation", IEEE Transactions on Power Apparatus and Systems, Vol. PAS-89, No. 3, pp. 363-369, March 1970.

[13] Zaborsky, J., Prasad, K.V., and Whang, K.W., "Stabilizing control in Emergencies: Part I. Equilibrium Point and State Determination," IEFE Transactions on Power Apparatus and Systems, Vo1. PAS100, No. 5, pp. 2374-2380, May, 1981.

[14] Zaborsky, J., Prasad, K.V., and Whang, "Stabilizing Control in Emergncies: Part 11. Control by Local Feedback," IEEE Transactions on Power Apparatus and Systems, VoT. PAS-100, No. 5, pp. $5381-$ 2389.
[15] IEEE Committee Report, "Power System Disturbance Monitoring: Utility Experience," IEEE Transactions on Power Systems, Vol. PWRS-3, No. 1, pp. 1340148, February, 1988.

[16] Rahimi, A., and Schaffer, G., "Power System Transient Stability Indexes for On-Line Analysis of 'Worst Case' Dynamic Contingencies," IEEE Iransactions on Power Systems, Vol. PWRS-2, No. 3, pp. 660-668, August, 1987 .

[17] Kirk, D. E., "Optimal Control Theory: An Introduction," Prentice Ha11. New York, 1970.

[18] Sage, and White, C. C., "Optimum Systems Control," Prentice-Hall, New Jersey, 1977.

[19] Xionagalas, T. C., Dasigi, S., and Singh, M. G., "Coordination in Hierarchical Algorithms," IEEE Transactions on Systems, Man, and Cybernetics, VoT. SMC-13, No. 3, pp. 397-406, May/June 1983.

[20] El-Abiad, A. H., and Nagappan, K., "Transient Stability Regions of Multimachine Power Systems," IEEE Transaction on Power Apparatus and Systems, Voi. PAS85 , pp. 169-179, February 1966 . 